\title{
Are patients with schizophrenia impaired in processing non-emotional features of human faces?
}

\author{
Hayley Darke ${ }^{1}$, Joel S. Peterman ${ }^{2}$, Sohee Park ${ }^{2}$, Suresh Sundram ${ }^{3,4}$ and Olivia Carter ${ }^{1 *}$ \\ 1 School of Psychological Sciences, University of Melbourne, Parkville, VIC, Australia \\ 2 Department of Psychology, Vanderbilt University, Nashville TN, USA \\ ${ }^{3}$ Department of Molecular Psychopharmacology, Florey Institute of Neuroscience and Mental Health, Parkville, VIC, Australia \\ ${ }^{4}$ Northern Psychiatry Research Centre, Epping, VIC, Australia
}

\section{Edited by:}

Randolph Blake, Vanderbilt

University, USA

Reviewed by:

Mandy Rossignol, University of Louvain, Belgium

Laura Germine, Massachusetts

General Hospital/Harvard Medical

School, USA

\section{*Correspondence:}

Olivia Carter, School of Psychological

Sciences, Faculty of Medicine,

Dentistry and Health Sciences,

University of Melbourne, Redmond

Barry Building, VIC 3010, Australia

e-mail:ocarter@unimelb.edu.au
It is known that individuals with schizophrenia exhibit signs of impaired face processing, however, the exact perceptual and cognitive mechanisms underlying these deficits are yet to be elucidated. One possible source of confusion in the current literature is the methodological and conceptual inconsistencies that can arise from the varied treatment of different aspects of face processing relating to emotional and non-emotional aspects of face perception. This review aims to disentangle the literature by focusing on the performance of patients with schizophrenia in a range of tasks that required processing of non-emotional features of face stimuli (e.g., identity or gender). We also consider the performance of patients on non-face stimuli that share common elements such as familiarity (e.g., cars) and social relevance (e.g., gait). We conclude by exploring whether observed deficits are best considered as "face-specific" and note that further investigation is required to properly assess the potential contribution of more generalized attentional or perceptual impairments.

Keywords: schizophrenia, vision, face, identity, detection, recognition, gait, perception

\section{INTRODUCTION}

Face processing deficits have been repeatedly demonstrated in patients with schizophrenia, however, debate continues regarding the precise nature of these impairments and the mechanisms that underlie them. Some authors posit that face processing deficits are specific to emotion-related content (Edwards et al., 2002; Schneider et al., 2006); others argue that they represent an impairment in processing biological and socially relevant stimuli (Kim et al., 2010); a more general impairment in visual attention (Caharel et al., 2007); or a generalized difficulty in processing complex visual stimuli-of which faces are just one example (Doop and Park, 2009). In contrast to the vast literature using tasks involving identification or recognition of facial expression and the relationship to impaired emotion processing (see Kohler et al., 2010), relatively little has been done to systematically assess face processing outside an emotional context in individuals with schizophrenia (c.f. a review in the current issue comparing face recognition deficits in schizophrenia and autism Watson, 2013). Before discussing the existing patient literature we will briefly consider the current theories of face processing more broadly.

\section{THE SEPARATION OF IDENTITY AND EXPRESSION PROCESSING}

The dominant theory of face perception as first proposed by Bruce and Young (1986) makes a division between identity and emotion recognition representing two largely independent processes. A neuroanatomical framework for this dual route model has since been provided by Haxby et al. (2000) and distinguishes between two types of information: invariant and changeable. Invariant information refers to properties that are consistent across different views and facial expressions, and is necessary for recognizing the identity of a face. Changeable information includes eye gaze, expression, and movements of the eyes and mouth, and is necessary for the recognition of facial affect. The initial processing of facial features is proposed to be mediated by neurons in the inferior occipital gyri (Haxby and Gobbini, 2011). From here, the analysis of "variant" or changeable visual features is processed largely via a route involving the posterior superior temporal sulcus (pSTS). In contrast, invariant (unchangeable) information is proposed to be processed via a ventral temporal route including the inferior occipital and fusiform gyri. These two routes then have differing degrees of connectivity with either limbic or cortical regions outside these face selective areas of visual extrastriate cortex.

Support for this separation of identity and expression recognition comes from a broad range of sources (for review see Calder and Young, 2005) including behavioral research (Bruce, 1986; Campbell, 1996; Calder et al., 2000), functional imaging studies (George et al., 1993; Sergent et al., 1994; Winston et al., 2004), and in dissociations exhibited by individuals with brain injury (Tranel et al., 1988; Young et al., 1993; Hornak et al., 1996) and prosopagnosia (Baudouin and Humphreys, 2006; Riddoch et al., 2008). Compelling neurophysiological evidence for this dissociation has also come from studies of non-human primates (Tsao et al., 2003; Pinsk et al., 2005; Rajimehr et al., 2009) where multiple "patches" of face-selective cortex have been identified that show selectivity to identity or expression processing, respectively (Tsao et al., 2008a,b). 
While this evidence demonstrates that identity and expression recognition involve separate processes, the level at which this bifurcation occurs, and the degree to which these parallel processes interact, are yet to be resolved. Importantly, it is also unclear the extent to which identity recognition and emotional processing are inextricably linked (Fitousi and Wenger, 2013; and for review see Calder, 2011). To properly understand the nature of face processing deficits in schizophrenia it is important to consider deficits in emotionally neutral judgments based on either changeable or invariant information.

\section{IDENTITY PROCESSING DEFICITS}

Deficits in non-emotional face processing have been demonstrated using a variety of behavioral tasks. However, heterogeneity across tasks types and participants has produced mixed results (see Table 1). Tasks that assess true identity processing are primarily matching tasks, where the participant views static photographs of faces (with non-face identifying features removed, such as hair and spectacles), either serially or concurrently. The participant must match the identity of the first face to one of several options (Addington and Addington, 1998; Penn et al., 2000; KucharskaPietura et al., 2005; Chen et al., 2012). The most commonly used face-matching task is the Benton Test of Facial Recognition (Benton, 1983; see Figure 1A). Individuals with schizophrenia have shown impaired performance on the Benton test in many (e.g., Addington and Addington, 1998; Evangeli and Broks, 2000; Whittaker et al., 2001; Hooker and Park, 2002; Kucharska-Pietura et al., 2005; Soria Bauser et al., 2012), but not all studies (Hall

Table 1 | Identity recognition tasks used in schizophrenia research from the last 20 years-All results relate to performance of Schizophrenia patients relative to controls.

$\begin{array}{lll}\text { Task Results } & \text { References }\end{array}$

\section{TASKS ASSESSING IDENTITY DISCRIMINATION}

Benton Test of Facial Recognition (see Significantly impaired

Figure 1A)
Borod et al., 19931; Kerr and Neale, 1993'; Bellack et al., 1996²; Mueser et al., 1996'; Salem et al., 1996¹; Addington and Addington, 1998'; Evangeli and Broks, 20001; Penn et al., 2000'; Whittaker et al., 2001²; Hooker and Park, 2002²; Not significantly impaired Kucharska-Pietura et al., 2005²; Soria Bauser et al., 20123 Hall et al., 2004'; Scholten et al., 20053'; Van 't Wout et al., 20071; Pomarol-Clotet et al., $2010^{3}$

Chen et al., 2009* Norton et al., 2009; Chen et al., 2012

Approaching significant impairment Not significantly impaired

(Match target to 1 of 2 choices)

Not significantly impaired

Hooker and Park, 2002

Neutral Face Recognition Task (Match target to 1 of 7 choices)
Identity Discrimination (same/different judgments of serially presented faces)
Significantly impaired Not significantly impaired
Martin et al., 2005; Butler et al., 2008; Shin et al., 2008 ${ }^{*}$; Soria Bauser et al., 2012; Edwards et al., 2001; Johnston et al., 2010; Soria Bauser et al., 2012

Identity Recognition Task (Is this Person

A or B?)

Significantly slower (accuracy at ceiling

Baudouin et al., 2002 for both groups)

\section{TASKS ASSESSING ONE ASPECT OF IDENTITY}

Morphed Sex Recognition Task

Not significantly impaired

Bediou et al., 2005, 2007, 2012

Age Discrimination Task (indicate the age

by decade: $1=$ teens ... 7 = seventies)

Not significantly

Schneider et al., 1998, 1995; Kohler et al., 2000

impaired-(speed/accuracy trade-off)

Significantly impaired

Age Discrimination Task (Judge whether Not significantly impaired

Significantly impaired

face is older or younger than 30) ORY FOR FACES

TASKS ASSESSING FA
Penn Face Memory Test

Significantly impaired

Gur et al., 2002a,b; Schneider et al., 2006

\section{Penn Face Memory Test}

The Warrington Recognition Memory

Test-Faces subtest

Significantly impaired Not significantly impaired

Famous Faces
Significantly impaired

Not significantly impaired
Sachs et al., 2004; Calkins et al., 2005*; Silver et al., 2009

Whittaker et al., 2001; Soria Bauser et al., 2012; Evangeli and Broks, 2000

Pomarol-Clotet et al., 2010; Evangeli and Broks, 2000; Whittaker et al., 2001; Joshua and Rossell, 2009*
Familiarity test for known and unknown

Significantly impaired

Caharel et al., 2007

${ }^{1}$ Short form, ${ }^{2}$ Long form, ${ }^{3}$ Not specified.

${ }^{*}$ Did not include a facial affect comparison task. 


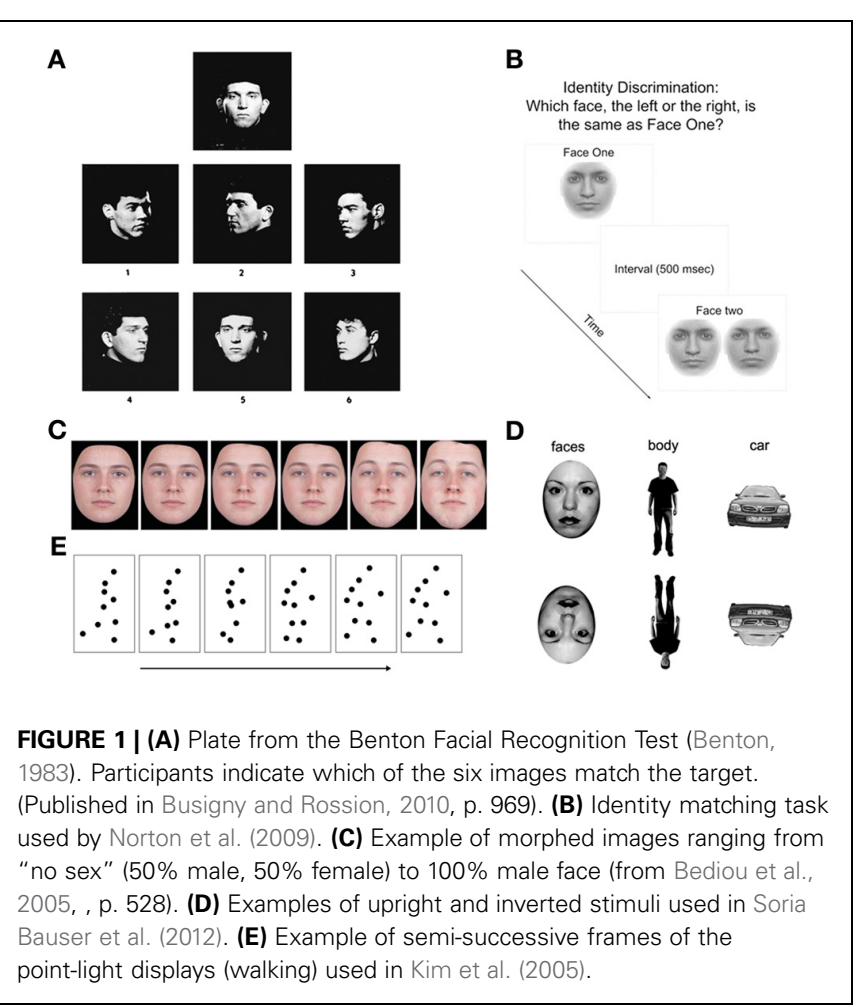

et al., 2004; Scholten et al., 2005; Van 't Wout et al., 2007; Pomarol-Clotet et al., 2010). One study using a booklet-based face-matching task with similar properties to the Benton also found no impairment (Hooker and Park, 2002). Three studies using a morphed identity-matching task-in which participants choose which of a pair of faces of varying similarity matches a briefly presented target-have also produced inconsistent results, with two studies reporting no impairment (Norton et al., 2009; Chen et al., 2012) and only one study approaching significance (Chen et al., 2009) (see Figure 1B). The reason for these inconsistent findings is unclear. Given the relatively heterogeneous patient samples, however, the influence of factors such as age, illness duration, and gender may be worth exploring through a formal meta-analysis in the future.

An alternative measure of identity recognition is the twoalternative forced-choice identity discrimination paradigm, in which the participant judges whether two serially presented faces are the same or different. Again, some studies reported significant impairment in schizophrenia (Martin et al., 2005; Butler et al., 2008; Shin et al., 2008; Soria Bauser et al., 2012) while others found no impairment relative to controls (Edwards et al., 2001; Johnston et al., 2010; Soria Bauser et al., 2012). Another study requiring participants to distinguish between photographs of two learned identities, person $\mathrm{A}$ and person $\mathrm{B}$, also reported significant impairment (Baudouin et al., 2002). Again, the reason for these inconsistent findings is unclear, but given that mean age and illness duration of the patients (Kucharska-Pietura et al, 2005), and the stimuli used in these tasks (e.g., Soria Bauser et al., 2012) are known to influence performance, it is possible these factors contributed here. While it is outside the scope of the current review it would be interesting to consider the relative severity of face perception deficits a non-clinical population of individuals high in psychosis-proneness and whether these deficits predict transition to psychosis. While impairments have been seen in some non-emotional aspects of face processing in these populations before (Poreh et al., 1994), they are not reported as frequently as deficits in face emotion perception (Waldeck and Miller, 2000; Williams et al., 2007; Germine and Hooker, 2011).

\section{SINGLE FEATURE IDENTIFICATION}

Tasks that do not assess true identity discrimination, but just one aspect of facial identity have produced more consistent results. For instance, (Bediou et al., 2005, 2007, 2012) found that patients with schizophrenia have an intact ability to discriminate the sex of faces that have been digitally morphed to increase ambiguity (see Figure 1C). Two studies (Schneider et al., 1995; Kohler et al., 2000) found that patients are significantly impaired in judging the age of a face in decades (i.e., teens, twenties, thirties, etc.), while one reported poorer accuracy, but faster reaction times than controls (Schneider et al., 1998). In contrast, one study found that patients were impaired in judging if a face is older or younger than 30 (Schneider et al., 2006), while two studies found no difference (Gur et al., 2002a,b). Taken together, these findings suggest that patients with schizophrenia are not impaired in their ability to make broad judgments about the sex or age of a face, but have greater difficulty on tasks that require more fine grained judgments. This result highlights the importance of selecting the right measure when assessing face recognition in schizophrenia. True identity perception likely reflects a judgment based on complex interactions between multiple facial features, so a task assessing just one aspect of face perception (such as sex) may not be a valid indicator of a true deficit in identity discrimination.

\section{IDENTITY RECOLLECTION AND FAMILIARITY}

Finally, tasks that assess memory of-as opposed to discrimination between - faces have largely revealed significant impairment in schizophrenia (Whittaker et al., 2001; Sachs et al., 2004; Calkins et al., 2005; Silver et al., 2009; Soria Bauser et al., 2012). In contrast, patients have been shown to have an intact ability to recognize famous faces (Evangeli and Broks, 2000; Whittaker et al., 2001; Joshua and Rossell, 2009; although one study reported significant impairment: Pomarol-Clotet et al., 2010), but are less accurate in familiarity judgment of photographs of strangers and known people (i.e., their doctor's face) (Caharel et al., 2007). However, these tasks are not necessarily an indicator of pure face processing in schizophrenia because this disorder is associated with general impairments in memory and new learning (Boyer et al., 2007). Again, care should be taken when employing memory-based face recognition tasks to ensure that general impairments in memory are taken into account.

\section{IMPAIRED FACE PROCESSING}

Face information is extracted from the environment using both face-specific and more general perceptual processes (McKone and Robbins, 2011). Some argue that face processing deficits in schizophrenia indeed represent dysfunction in face-specific perceptual processes-generally referred to as "holistic face 
processing." This represents a rapid, involuntary face-specific perceptual process that integrates information across the face as a whole. It includes such information as the shapes of individual features, the relative distances between them, and the contour of the cheeks and jaw (Maurer et al., 2002; McKone and Yovel, 2009). This process is specific to invariant face information, and is therefore critical for perceiving identity (McKone and Robbins, 2011). For instance, it has been demonstrated in healthy controls that holistic processing predicts an individual's ability to remember and distinguish between faces (Richler et al., 2011). Similarly, it has been shown that individuals with congenital prosopagnosia (inability to recognize faces) perform poorly on holistic processing tasks (Palermo et al., 2011).

One common means of evaluating holistic processing is with the Face Inversion Effect-observed as a reduction in face discrimination performance for inverted faces compared to upright faces (see Figure 1D). The magnitude of this effect is thought to represent a loss of holistic information crucial to face discrimination, and is disproportionately larger for faces compared to other non-face stimuli (Yin, 1969). Studies of holistic processing in schizophrenia produced varied results, with some studies reporting normal inversion effects for faces (Schwartz et al., 2002; Chambon et al., 2006; Butler et al., 2008), while others report reduced inversion effects compared to controls (Shin et al., 2008; Kim et al., 2010; Soria Bauser et al., 2012). In particular, Shin et al. (2008) reported that patients with schizophrenia were more impaired when discriminating faces that differed in configural information, rather than featural information. An electrophysiological indicator of the face inversion effect is the N170 (Eimer, 2000), a negative potential seen using electroencephalography (EEG). The N170 is reduced in patients with schizophrenia while viewing inverted faces (Onitsuka et al., 2006; Ibáñez et al., 2012), and is associated with lower scores on measures of social functioning (Obayashi et al., 2009; Tsunoda et al., 2012). These findings suggest there may be an underlying face processing abnormality that may go undetected by commonly used behavioral measures.

In a related behavioral study, Schwartz et al. (2002) employed the composite face task, which is considered to provide a more rigorous measure of holistic processing than other inversion tasks (McKone, 2008). In this task, participants are required to make decisions about the upper halves of faces while ignoring the lower halves. These face halves are either aligned to form a complete face (producing an interference effect) or misaligned (removing the interference). When the stimuli are inverted, however, the aligned faces no longer produce strong interference effects. It was found that patients with schizophrenia showed typical patterns of interference for upright faces and not inverted faces. While this study has not been repeated, it provides support for the argument that holistic processing is largely preserved in schizophrenia and appears to contradict some of the results using the face inversion effect.

\section{EVIDENCE FOR IDENTITY PROCESSING DEFICITS USING NON-FACE STIMULI}

As outlined above, a number of studies have shown impaired performance on tasks aimed to assess face-specific processing.
However, a number of similar deficits seem to be apparent on tasks using non-face stimuli. For example, Soria Bauser et al. (2012) reported reduced inversion effects for cars and bodies (see Figure 1D) that mirrored their findings using face stimuli, suggesting an impairment that encompasses more than just facespecific holistic processing. An interesting comparison is also provided by research looking at gait perception. Previous research has indicated that the identity of an individual can also be extracted from an individual's gait pattern (Cutting and Kozlowski, 1977). Through the use of point-light displays (PLD; Johansson, 1973), visually impoverished stimuli provide body form and structure solely through motion cues of coordinated dots (see Figure 1E). Similar to the ERP findings regarding face processing, the N170 component has also been found in healthy individuals during visual processing of inverted PLD and static images of bodies (Stekelenburg and de Gelder, 2004; Jokisch et al., 2005). Loula et al. (2005) demonstrated that healthy subjects exhibited superior performance in identifying self and friend's movement when compared to a stranger's movement. Furthermore, inverting the PLD resulted in chance performance across all three conditions. Unfortunately the use of dynamic gait stimuli in the investigation of true identity recognition deficits in schizophrenia has yet to be conducted. Individuals with schizophrenia are impaired in discriminating PLD-presented body movements (biological motion) from scrambled PLD body movements (Kim et al., 2005). It is therefore, conceivable that the ability to use the information provided in the point-light displays to extract identify information would also be impaired.

\section{DOES IMPAIRED IDENTITY PROCESSING REFLECT A GENERALIZED ATTENTIONAL DEFICIT?}

One possible account for face processing deficits in schizophrenia is that they are the result of a more general impairment in allocating visuospatial attention (Baudouin et al., 2002). One suggestion is an impairment in global vs. local visual processing. "Global processing" refers to the ability to attend to any visual stimulus as a "whole," as opposed to its component features (Tan et al., 2009). Studies of schizophrenia have revealed impairments in global processing, but largely preserved local processing both for static (Goodarzi et al., 2000; Silverstein et al., 2000; Johnson et al., 2005; Poirel et al., 2010) and dynamic stimuli (Chen et al., 2003). In addition, patients with schizophrenia demonstrate a bias toward attending to the local level of a stimulus, even when task demands favor a global strategy (Landgraf et al., 2011).

It is possible that a global processing deficit could contribute to impairments in identity recognition because the important global-level information is not being processed efficiently. For instance, it has been shown that identity recognition performance is improved when healthy participants are primed to adopt a global processing strategy, and impaired when primed with a local processing strategy (Macrae and Lewis, 2002; Perfect, 2003). Patients with schizophrenia similarly showed less of a reduction in identity recognition performance compared to controls when configural cues were removed from a face (Joshua and Rossell, 2009), indicating that these individuals relied more strongly on local features when identifying famous faces. Global processing deficits could also explain the expected deficits in 
identity recognition from gait in individuals with schizophrenia. Kim et al. (2005) argued that deficits in biological motion perception in individuals with schizophrenia may arise due to their well-documented difficulties in global motion perception (for review see Chen, 2011).

\section{DOES IMPAIRED FACE IDENTITY PROCESSING REFLECT A GENERAL VISUAL PERCEPTUAL DIFFICULTY?}

Individuals with schizophrenia show a gamut of visual perceptual impairments (see Butler et al., 2008 and the editorial of this research topic!). These difficulties include form processing such as object recognition, grouping, perceptual closure, and visual context (Place and Gilmore, 1980; Saccuzzo and Braff, 1986; Rief, 1991; Kerr and Neale, 1993; Rabinowicz et al., 1996; Kohler et al., 2000; Silverstein et al., 2000; Doniger et al., 2002; Brenner et al., 2003; Uhlhaas et al., 2006; Kurylo et al., 2007; Yang et al., 2013). Moreover, neuroanatomical data indicate that the visual cortex in schizophrenia is abnormal with respect to the density of neurons (Selemon et al., 1995), total number of neurons (Dorph-Petersen et al., 2007) and GABA concentration in the visual cortex that is associated with orientation-specific center-surround suppression (Yoon et al., 2010). Interestingly, the face fusiform area (FFA) seems relatively intact, at least functionally (Yoon et al., 2006). Given the exhaustive list of basic visual perceptual deficits in schizophrenia, it seems likely that processing of complex visual stimuli such as faces would also be compromised. Thus, it is likely

\section{REFERENCES}

Addington, J., and Addington, D. (1998). Facial affect recognition and information processing in schizophrenia and bipolar disorder. Schizophr. Res. 32, 171-181. doi: 10.1016/S0920-996400042-5

Baudouin, J.-Y., and Humphreys, G. W. (2006). Compensatory strategies in processing facial emotions: evidence from prosopagnosia. Neuropsychologia 44, 1361-1369. doi: 10.1016/j.neuropsychologia. 2006.01.006

Baudouin, J.-Y., Martin, F., Tiberghien, G., Verlut, I., and Franck, N. (2002). Selective attention to facial emotion and identity in schizophrenia. Neuropsychologia 40, 503-511. doi: $\quad 10.1016 /$ S0028-393200114393200112

Bediou, B., Asri, F., Brunelin, J., Krolak-Salmon, P., d'Amato, T., Saoud, M., et al. (2007). Emotion recognition and genetic vulnerability to schizophrenia. $\mathrm{Br}$. J. Psychiatry 191, 126-130. doi: 10.1192/bjp.bp.106.028829

Bediou, B., Brunelin, J., d' Amato, T., Fecteau, S., Saoud, M., Hénaff, M.-A., et al. (2012). A comparison of facial emotion processing in neurological and psychiatric conditions. Front. Psychol. 3:98. doi: 10.3389/fpsyg.2012.00098
Bediou, B., Krolak-Salmon, P., Saoud, M., Henaff, M.-A., Burt, M., Dalery, J., et al. (2005). Facial expression and sex recognition in schizophrenia and depression. Can. J. Psychiatry 50, 525-533.

Bellack, A. S., Blanchard, J. J., and Mueser, K. T. (1996). Cue availability and affect perception in schizophrenia. Schizophr. Bull. 22, 535-544. doi: 10.1093/schbul/22.3.535

Benton, A. L. (1983). Contributions to Neuropsychological Assessment: A Clinical Manual. New York, NY: Oxford University Press. M., Brozgold, A., and Welkowitz, J. (1993). Perception of facial emotion in schizophrenic and J. Nerv. Ment. Dis. 181, 494-502. doi: 10.1097/00005053-19930800000004

Boyer, P., Phillips, J. L., Rousseau, F. L., and Ilivitsky, S. (2007). Hippocampal abnormalities and memory deficits: new evidence of a strong pathophysiological link in schizophrenia. Brain Res. Rev. 54, 92-112. doi: 10.1016/j.brainresrev.2006.12.008

Brenner, C. A., Wilt, M. A., Lysaker, P. H., Koyfman, A., and O'Donnell, B. F. (2003). Psychometrically
Borod, J. C., Martin, C. C., Alpert, right brain-damaged patients.

that at least some aspects of face processing deficits observed in schizophrenia arise from visual cortical abnormalities.

\section{CONCLUSIONS}

Deficits in face processing have frequently been observed in patients with schizophrenia. In order to fully understand the mechanisms underlying these impairments it is important to consider the relative contribution of the multiple factors that may be involved. The fact that deficits have been seen in face identity tasks without an emotional/expression recognition component suggests that these deficits are unlikely to be limited to emotion processing. Moreover, the observation of more generalized impairments in visual and attentional function in these patients also raises questions about whether there is indeed anything special about faces at all. Lastly, the potential role of medication in these impairments has yet to be clearly determined. It is only through future controlled studies that balance difficulty across memory, attentional and perceptual demands—or directly assess the capacities - that we will begin to understand how face processing deficits emerge in these patients.

\section{ACKNOWLEDGMENTS}

This work was supported by an Australian National Health and Medical Research council fellowship \# 628590 to Olivia Carter, National Institute on Mental Health T32 MH018921-21A1 to Joel S. Peterman, Vanderbilt International Office Grant to Sohee Park.

matched visual-processing tasks in schizophrenia spectrum disorders. J. Abnorm. Psychol. 112, 28-37. doi: 10.1037/0021-843X.112.1.28

Bruce, V. (1986). Influences of familiarity on the processing of faces. Perception 15, 387-397. doi: 10.1068/p150387

Bruce, V., and Young, A. (1986). Understanding face recognition. Br. J. Psychol. 77, 305-327. doi: 10.1111/j.20448295.1986.tb02199.x

Busigny, T., and Rossion, B. (2010). Acquired prosopagnosia abolishes the face inversion effect. Cortex 46, 965-981. doi: 10.1016/j.cortex.2009.07.004

Butler, P. D., Tambini, A., Yovel, G., Jalbrzikowski, M., Ziwich, R., Silipo, et al. (2008). What's in a face. effects of stimulus duration and inversion on face processing in schizophrenia. Schizophr. Res. 103, 283-292. doi: 10.1016/j.schres.2008.03.007

Caharel, S., Bernard, C., Thibaut, F., Haouzir, S., Di Maggio-Clozel, C., Allio, G., et al. (2007). The effects of familiarity and emotional expression on face processing examined by ERPs in patients with schizophrenia. Schizophr. Res. 95, 186-196. doi: 10.1016/j.schres.2007.06.015

Calder, A. J. (2011). "Does facial identity and facial expression recognition involve separate visual routes?" in The Oxford Handbook of Face Perception, eds A. J. Calder, G. Rhodes, M. H. Johnson, and J. V. Haxby (Oxford: Oxford University Press), 427-448. doi: 10.1093/ oxfordhb/9780199559053.013.0022

Calder, A. J., and Young, A. W. (2005). Understanding the recognition of facial identity and facial expression. Nat. Rev. Neurosci. 6, 641-651. doi: 10.1038/nrn1724

Calder, A. J., Young, A. W., Keane, J., and Dean, M. (2000). Configural information in facial expression perception. J. Exp. Psychol. Hum. Percept. Perform. 26, 527-551. doi: 10.1037/0096-1523.26.2.527

Calkins, M. E., Gur, R. C., Ragland, J. D., and Gur, R. E. (2005). Face recognition memory deficits and visual object memory performance in patients with schizophrenia and their relatives. Am. J. Psychiatry 162, 1963-1966. doi: 10.1176/appi.ajp.162.10.1963

Campbell, R. (1996). Dissociating face processing skills: decisions about lip read speech, expression, and identity. Q. J. Exp. Psychol. A 49, 295-314.

Chambon, V., Baudouin, J. Y., and Franck, N. (2006). The role of configural information in facial emotion recognition in 
schizophrenia. Neuropsychologia 44, 2437-2444. doi: 10.1016/j. neuropsychologia.2006.04.008

Chen, Y. (2011). Abnormal visual motion processing in schizophrenia: a review of research progress. Schizophr. Bull. 37, 709-715. doi: 10.1093/schbul/sbr020

Chen, Y., Cataldo, A., Norton, D. J., and Ongur, D. (2012). Distinct facial processing in schizophrenia and schizoaffective disorders. Schizophr. Res. 134, 95-100. doi: 10.1016/j.schres.2011.08.001

Chen, Y., Nakayama, K., Levy, D., Matthysse, S., and Holzman, P. (2003). Processing of global, but not local, motion direction is deficient in schizophrenia. Schizophr. Res. 61, 215-227. doi: 10.1016/S0920996400222-0

Chen, Y., Norton, D., McBain, R., Ongur, D., and Heckers, S. (2009). Visual and cognitive processing of face information in schizophrenia: detection, discrimination and working memory. Schizophr. Res. 107, 92-98. doi: 10.1016/j.schres.2008.09.010

Cutting, J. E., and Kozlowski, L. T. (1977). Recognising friends by their walk: gait perception without familiarity cues. Bull. Psychon. Soc. 9, 353-356.

Doniger, G. M., Foxe, J. J., Murrary, M. M., Higgins, B. A., and Javitt, D. C. (2002). Impaired visual object recognition and dor$\mathrm{sal} /$ ventral stream interaction in schizophrenia. Arch. Gen. Psychiatry 59, 1011-1020. doi: 10.1001/archpsyc.59.11.1011

Doop, M. L., and Park, S. (2009). Facial expression and face orientation processing in schizophrenia. Psychiatry Res. 170, 103-107. doi: 10.1016/j.psychres.2009.06.009

Dorph-Petersen, K. A., Pierri, J. N., Wu, Q., Sampson, A. R., and Lewis, D. A. (2007). Primary visual cortex volume and total neuron number are reduced in schizophrenia. J. Comp. Neurol. 501, 290-301. doi: $10.1002 /$ cne. 21243

Edwards, J., Jackson, H. J., and Pattison, P. E. (2002). Emotion recognition via facial expression and affective prosody in schizophrenia: a methodological review. Clin. Psychol. Rev. 22, 789-832. doi: 10.1016/S0272-735800130-7

Edwards, J., Pattison, P. E., Jackson, H. J., and Wales, R. J. (2001). Facial affect and affective prosody recognition in first-episode schizophrenia. Schizophr. Res. 48, 235-253. doi: 10.1016/S0920-996400099-2

Eimer, M. (2000). The face-specific N170 component reflects late stages in the structural encoding of faces. Cogn. Neurosci. 11, 2319-2324.

Evangeli, M., and Broks, P. (2000). Face processing in schizophrenia: parallels with the effects of amygdala damage. Cogn. Neuropsychiatry 5, 81-104. doi: 10.1080/135468000395754

Fitousi, D., and Wenger, M. J. (2013). Variants of independence in the perception of facial identity and expression. J. Exp. Psychol. Hum. Percept. Perform. 39, 135-155. doi: 10.1037/a0028001

George, M. S., Ketter, T. A., Gill, D. S., Haxby, J. V., Ungerleider, L. G., Herscovitch, P., et al. (1993). Brain regions involved in recognizing facial emotion or identity: an oxygen-15 PET study. Neurosciences $5,384-394$.

Germine, L. T., and Hooker, C. I. (2011). Face emotion recognition is related to individual differences in psychosis-proneness. Psychol. Med. 41, 937-947. doi: 10.1017/S0033291710001571

Goodarzi, M. A., Wykes, T., and Hemsley, D. R. (2000). Cerebral lateralization of global-local processing in people with schizotypy. Schizophr. Res. 45, 115-121. doi: 10.1016/S0920-996400173-5

Gur, R. C., Schroeder, L., Turner, T., McGrath, C., Chan, R. M., Turetsky, B. I., et al. (2002a). Brain activation during facial emotion processing. Neuroimage 16, 651-662. doi: 10.1006/nimg.2002.1097

Gur, R. E., McGrath, C., Chan, R. M., Schroeder, L., Turner, T., Turetsky, B. I., et al. (2002b). An fMRI study of facial emotion processing in patients with schizophrenia. Am. J. Psychiatry 159, 1992-1999. doi: 10.1176/appi.ajp.159.12.1992

Hall, J., Harris, J. M., Sprengelmeyer, R., Sprengelmeyer, A., Young, A. W., Santos, I. M., et al. (2004). Social cognition and face processing in schizophrenia. Br. J. Psychiatry 185, 169-170. doi: 10.1192/bjp.185.2.169

Haxby, J. V., and Gobbini, M. I. (2011). "Distributed neural systems for face perception," in The Oxford Handbook of Face Perception, eds M. H. Johnson and J. V. Haxby (Oxford: Oxford University Press), 93-110. doi: 10.1093/oxfordhb/ 9780199559053.013.0006

Haxby, J. V., Hoffman, E. A., and Gobbini, M. I. (2000). The distributed human neural system for face perception. Trends Cogn. Sci. 4, 223-233. doi: 10.1016/S1364661301482-0

Hooker, C., and Park, S. (2002). Emotion processing and its relationship to social functioning in schizophrenia patients. Psychiatry Res. 112, 41-50. doi: 10.1016/S0165178100177-4

Hornak, J., Rolls, E. T., and Wade, D. (1996). Face and voice expression identification in patients with emotional and behavioural changes following ventral frontal lobe damage. Neuropsychologia 34 , 247-261. doi: 10.1016/0028393200106-9

Ibáñez, A., Riveros, R., Hurtado, E., Gleichgerrcht, E., Urquina, H., Herrera, E., et al. (2012). The face and its emotion: right N170 deficits in structural processing and early emotional discrimination in schizophrenic patients and relatives. Psychiatry Res. 195, 18-26. doi: 10.1016/j.psychres.2011.07.027

Johansson, G. (1973). Visual perception of biological motion and a model for its analysis. Percept. Psychophys. 14, 201-211. doi: 10.3758/BF03212378

Johnson, S. C., Lowery, N., Kohler, C., and Turetsky, B. I. (2005). Global-local visual processing in schizophrenia: evidence for an early visual processing deficit. Biol. Psychiatry 58, 937-946. doi: 10.1016/j.biopsych.2005.04.053

Johnston, P. J., Enticott, P. G., Mayes, A. K., Hoy, K. E., Herring, S. E., and Fitzgerald, P. E. (2010). Symptom correlates of static and dynamic facial affect processing in schizophrenia: evidence of a double dissociation. Schizophr. Bull. 36, 680-687. doi: 10.1093/schbul/sbn136

Jokisch, D., Daum, I., Suchan, B. and Troje, N. (2005). Structural encoding and recognition of biological motion: evidence from eventrelated potentials and source analysis. Behav. Brain Res. 157, 195-204. doi: 10.1016/j.bbr.2004.06.025

Joshua, N., and Rossell, S. (2009). Configural face processing in schizophrenia. Schizophr. Res. 112, 99-103. doi: 10.1016/j.schres.2009.03.033

Kerr, S. L., and Neale, J. M (1993). Emotion perception in schizophrenia: specific deficit or further evidence of generalized poor performance. J. Abnorm. Psychol. 102, 312-318. doi: 10.1037/0021-843X.102.2.312

Kim, H. S., Shin, N. Y., Choi, J.-S., Jung, M. H., Jang, J. H., Kang, D.-H., et al. (2010). Processing of facial configuration in individuals at ultra-high risk for schizophrenia. Schizophr. Res. 118, 81-87. doi: 10.1016/j.schres.2010.01.003

Kim, J., Doop, M. L., Blake, R., and Park, S. (2005). Impaired visual recognition of biological motion in schizophrenia. Schizophr. Res. 77, 299-307. doi: 10.1016/j.schres.2005.04.006

Kohler, C. G., Bilker, W., Hagendoorn, M., Gur, R. E., and Gur, R. C. (2000). Emotion recognition deficit in schizophrenia: association with symptomatology and cognition. Biol. psychiatry 48, 127-136. doi: 10.1016/S0006-322300847-7

Kohler, C. G., Walker, J. B., Martin, E. A., Healey, K. M., and Moberg, P. J. (2010). Facial emotion perception in schizophrenia: a meta-analytic review. Schizophr. Bull. 36, 1009-1019. doi: $10.1093 /$ schbul/sbn192

Kucharska-Pietura, K., David, A. S., Masiak, M., and Phillips, M. L. (2005). Perception of facial and vocal affect by people with schizophrenia in early and late stages of illness. Br. J. Psychiatry 187, 523-528. doi: 10.1192/bjp.187.6.523

Kurylo, D. D., Pasternak, R., Silipo, G., Javitt, D. C., and Butler, P. D. (2007). Perceptual organization by proximity and similarity in schizophrenia. Schizophr. Res. 95, 205-214. doi: 10.1016/j.schres.2007.07.001

Landgraf, S., Amado, I., Purkhart, R., Ries, J., Olié, J.-P., and van der Meer, E. (2011). Visuo-spatial cognition in schizophrenia: confirmation of a preference for local information processing. Schizophr. Res. 127, 163-170. doi: 10.1016/j.schres.2010.11.027

Loula, F., Prasad, S., Harber, K., and Shiffrar, M. (2005). Recognizing people from their movement. J. Exp. Psychol. Hum. Percept. Perform. 31, 210-220. doi: 10.1037/0096-1523. 31.1 .210

Macrae, C. N., and Lewis, H. L. (2002). Do I know you. Processing orientation and face recognition. Psychol. Sci. 13, 194-196. doi: 10.1111/14679280.00436

Martin, F., Baudouin, J.-Y., Tiberghien, G., and Franck, N. (2005). Processing emotional expression and facial identity in schizophrenia. Psychiatry Res. 134, 43-53. doi 10.1016/j.psychres.2003.12.031

Maurer, D., Le Grand, R., and Mondloch, C. J. (2002). The many faces of configural processing. Trends Cogn. Sci. 6, 255-260. doi: 10.1016/S1364-661301903-4

McKone, E. (2008). Holistic processing for faces operates over a wide range of sizes but is strongest at identification rather than conversational distances. Vision Res. 49, 268-283. doi: 10.1016/j.visres.2008.10.020

McKone, E., and Robbins, R. (2011). "Are faces special," in The Oxford 
Handbook of Face Perception, eds A. J., Calder, G., Rhodes, M. H. Johnson, and J. V. Haxby (Oxford: Oxford University Press), 149-176. doi: 10.1093/oxfordhb/ 9780199559053.013.0009

McKone, E., and Yovel, G. (2009). Why does picture-plane inversion sometimes dissociate perception of features and spacing in faces, and sometimes not. toward a new theory of holistic processing. Psychon. Bull. Rev. 16, 778-797. doi: 10.3758/PBR.16.5.778

Mueser, K. T., Doonan, R., Penn, D. L., Blanchard, J. J., Bellack, A. S., Nishith, P., et al. (1996). Emotion recognition and social competence in chronic schizophrenia. J. Abnorm. Psychol. 105, 271-275. doi: 10.1037/0021-843X.105.2.271

Norton, D., McBain, R., Holt, D. J., Ongur, D., and Chen, Y. (2009). Association of impaired facial affect recognition with basic facial and visual processing deficits in schizophrenia. Biol. Psychiatry 65, 1094-1098. doi: 10.1016/j.biopsych.2009.01.026

Obayashi, C., Nakashima, T., Onitsuka, T., Maekawa, T., Hirano, Y., Hirano, S., et al. (2009). Decreased spatial frequency sensitivities for processing faces in male patients with chronic schizophrenia. Clin. Neurophysiol. 120, 1525-1533. doi: 10.1016/j.clinph.2009.06.016

Onitsuka, T., Niznikiewicz, M. A., Spencer, K. M., Frumin, M., Kuroki, N., Lucia, L. C., et al. (2006). Functional and structural deficits in brain regions subserving face perception in schizophrenia. Am. J. Psychiatry 163, 455-462. doi: 10.1176/appi.ajp.163.3.455

Palermo, R., Willis, M. L., Rivoltac, D., McKone, E., Wilson, C. E., and Caldera, A. J. (2011). Impaired holistic coding of facial expression and facial identity in congenital prosopagnosia. Neuropsychologia 49, 1226-1235. doi: $10.1016 / \mathrm{j}$. neuropsychologia.2011.02.021

Penn, D. L., Combs, D. R., Ritchie, M., Francis, J., Cassisi, J., Morris, S., et al. (2000). Emotion recognition in schizophrenia: further investigation of versus specific deficit models. J. Abnorm. Psychol. 109, 512-516. doi: 10.1037/0021-843X.109.3.512

Perfect, T. J. (2003). Local processing bias impairs line-up performance. Psychol. Rep. 93, 393-394.

Pinsk, M. A., DeSimone, K., Moore, T., Gross, C. G., and Kastner, S. (2005). Representations of faces and body parts in macaque temporal cortex: a functional MRI study. Proc. Natl.
Acad. Sci. U.S.A. 102, 6996-7001. doi: $10.1073 /$ pnas. 0502605102

Place, E. J., and Gilmore, G. C. (1980). Perceptual organization in schizophrenia. J. Abnorm. Psychol. 89, 409-418. doi: 10.1037/0021843X.89.3.409

Poirel, N., Brazo, P., Turbelin, M.-R., Lecardeur, L., Simon, G., Houdé, O., et al. (2010). Meaningfulness and global-local processing in schizophrenia. Neuropsychologia 48, 3062-3068. doi: 10.1016/j. neuropsychologia.2010.06.017

Pomarol-Clotet, E., Hynes, F., Ashwin, C., Bullmore, E. T., McKenna, P. J., and Laws, K. R. (2010). Facial emotion processing in schizophrenia: a non-specific neuropsychological deficit. Psychol. Med. 40, 911-919. doi: 10.1017/S0033291709991309

Poreh, A. M., Whitman, R. D., Weber M., and Ross, T. (1994). Facial recognition in hypothetically schizotypic college students: the role of generalized poor performance. J. Nerv. Ment. Dis. 182, 503-507. doi: 10.1097/00005053199409000-00005

Rabinowicz, E. F., Opler, L. A., Owen, D. R., and Knight, R. A. (1996). Dot Enumeration Perceptual Organization Task (DEPOT): evidence for a short-term visual memory deficit in schizophrenia. J. Abnorm. Psychol. 105, 336-348. doi: 10.1037/0021-843X.105.3.336

Rajimehr, R., Young, J. C., and Tootell, R. B. (2009). An anterior temporal face patch in human cortex, predicted by macaque maps. Proc. Natl. Acad. Sci. U.S.A. 106, 1995-2000 doi: 10.1073/pnas.0807304106

Richler, J. J., Cheung, O. S., and Gauthier, I. (2011). Holistic processing predicts face recognition. Psychol. Sci. 22, 464-471. doi: 10.1177/0956797611401753

Riddoch, M. J., Johnston, R. A. Bracewell, R. M., Boutsen, L., and Humphreys, G. W. (2008). Are faces special. A case of pure prosopagnosia. Cogn. Neuropsychol. 25, 3-26. doi: 10.1080/02643290801920113

Rief, W. (1991). Visual perceptual organization in schizophrenic patients. Br. J. Clin. Psychol. 30, 359-366. doi: 10.1111/j.20448260.1991.tb00956.x

Saccuzzo, D. P., and Braff, D. L. (1986). Information-processing abnormalities: trait- and state-dependent components. Schizophr. Bull. 12, 447-459. doi: $10.1093 / \mathrm{schbul} / 12.3 .447$

Sachs, G., Steger-Wuchse, D., Kryspin-Exner, I., Gur, R. C., and Katschnig, H. (2004). Facial recognition deficits and cognition in schizophrenia. Schizophr. Res. 68, 27-35. doi 10.1016/S0920-996400131-2

Salem, J. E., Kring, A. M., and Kerr S. L. (1996). More evidence for generalized poor performance in facial emotion perception in schizophrenia. J. Abnorm. Psychol. 105, 480-483. doi: 10.1037/0021-843X.105.3.480

Schneider, F., Gur, R. C., Gur, R. E., and Shtasel, D. L. (1995). Emotional processing in schizophrenia: neurobehavioral probes in relation to psychopathology. Schizophr. Res. 17, 67-75. doi: 10.1016/0920-996400031-G

Schneider, F., Gur, R. C., Koch, K., Backes, V., Amunts, K., Shah, N. J., et al. (2006). Impairment in the specificity of emotion processing in schizophrenia. Am. J. Psychiatry 163, 442-447. doi 10.1176/appi.ajp.163.3.442

Schneider, F., Weiss, U., Kessler, C., Salloum, J. B., Posse, S., Grodd, S. et al. (1998). Differential amygdala activation in schizophrenia during sadness. Schizophr. Res. 34, 133-142. doi: 10.1016/S0920-996400085-1

Scholten, M. R., Aleman, A., Montagne, B., and Kahn, R. S. (2005) Schizophrenia and processing of facial emotion: sex matters. Schizophr. Res. 78, 61-67. doi 10.1016/j.schres.2005.06.019

Schwartz, B. L., Marvel, C. L., Drapalski, A., Rosse, R. B., and Deutsch, S. I. (2002). Configural processing in face recognition in schizophrenia. Cogn. Neuropsychiatry 7, 15-39. doi 10.1080/13546800143000113

Selemon, L. D., Rajkowska, G., and Goldman-Rakic, P. S. (1995). Abnormally high neuronal density in the schizophrenic cortex: a morphometric analysis of prefrontal area 9 and occipital area 17. Arch. Gen. Psychiatry 52, 805. doi: 10.1001/archpsyc. 1995.03950220015005

Sergent, J., Ohta, S., Macdonald, B., and Zuck, E. (1994). Segregated processing of facial identity and emotion in the human brain: a PET study. Vis. Cogn. 1, 349-369. doi: 10.1080/13506289408402305

Shin, Y.-W., Na, M. H., Ha, T. H., Kang, D.-H., Yoo, S.-Y., and Kwon, J. S. (2008). Dysfunction in configural face processing in patients with schizophrenia. Schizophr. Bull. 34, 538-543. doi: $10.1093 / \mathrm{schbul} / \mathrm{sbm} 118$

Silver, H., Bilker, W., and Goodman, C. (2009). Impaired recognition of happy, sad and neutral expressions in schizophrenia is emotion, but not valence, specific and context dependent. Psychiatry Res. 169, 101-106. doi: 10.1016/j.psychres.2008.11.017

Silverstein, S. M., Kovács, I., Corry, R., and Valone, C. (2000). Perceptual organization, the disorganization syndrome, and context processing in chronic schizophrenia. Schizophr. Res. 43, 11-20. doi: 10.1016/S0920996400180-2

Soria Bauser, D., Thoma, P., Aizenberg, V., Brüne, M., Juckel, G., and Daum, I. (2012). Face and body perception in schizophrenia: a configural processing deficit. Psychiatry Res. 195 9-17. doi: 10.1016/j.psychres.2011. 07.017

Stekelenburg, J. J., and de Gelder, B. (2004). The neural correlates of perceiving human bodies: an ERP study on the body-inversion effect. Neuroreport 15, 777-780. doi: 10.1097/00001756-20040409000007

Tan, H. K., Jones, G. V., and Watson, D. G. (2009). Encouraging the perceptual underdog: positive affective priming of nonpreferred local-global processes. Emotion 9, 238-247. doi: 10.1037/a0014713

Tranel, D., Damasio, A. R., and Damasio, H. (1988). Intact recognition of facial expression, gender, and age in patients with impaired recognition of face identity. Neurology 38, 690-690. doi: 10.1212/WNL.38.5.690

Tsao, D. Y., Freiwald, W. A., Knutsen, T. A., Mandeville, J. B., and Tootell, R. B. (2003). Faces and objects in macaque cerebral cortex. Nat. Neurosci. 6, 989-995. doi: 10.1038/nn1111

Tsao, D. Y., Moeller, S., and Freiwald, W. A. (2008a). Comparing face patch systems in macaques and humans. Proc. Natl. Acad. Sci.U.S.A. 105, 19514-19519. doi: 10.1073/ pnas. 0809662105

Tsao, D. Y., Schweers, N., Moeller, S., and Freiwald, W. A. (2008b). Patches of face-selective cortex in the macaque frontal lobe. Nat. Neurosci. 11, 877-879. doi: 10.1038/ nn.2158

Tsunoda, T., Kanba, S., Ueno, T., Hirano, Y., Hirano, S., Maekawa, T., et al. (2012). Altered face inversion effect and association between face N170 reduction and social dysfunction in patients with schizophrenia. Clin. Neurophysiol. 123, 1762-1768. doi: 10.1016/j.clinph.2012.01.024

Uhlhaas, P. J., Phillips, W. A., Mitchell, G., and Silverstein, S. M. (2006). Perceptual grouping in disorganized schizophrenia. Psychiatry Res. 145, 105-117. doi: 10.1016/j.psychres. 2005.10.016 
Van 't Wout, M., Aleman, A., Kessels, R. P., Cahn, W., de Haan, E. H., and Kahn, R. S. (2007). Exploring the nature of facial affect processing deficits in schizophrenia. Psychiatry Res. 150, 227-235. doi: 10.1016/j. psychres.2006.03.010

Waldeck, T. L., and Miller, L. S. (2000). Social skills deficits in schizotypal personality disorder. Psychiatry Res. 93, 237-246. doi: 10.1016/S0165178100122-0

Watson, T. L. (2013). Implications of holistic face processing in autism and schizophrenia. Front. Psychol. 4:414. doi: 10.3389/fpsyg.2013.00414

Whittaker, J. F., Deakin, J. F., and Tomenson, B. (2001). Face processing in schizophrenia: defining the deficit. Psychol. Med. 31, 499-507. doi: 10.1017/S0033291701003701

Williams, B. T., Henry, J. D., and Green, M. J. (2007). Facial affect recognition and schizotypy. Early
Interv. Psychiatry 1, 177-182. doi: 10.1111/j.1751-7893.2007.00023.x

Winston, J. S., Henson, R. N., FineGoulden, M. R., and Dolan, R. J. (2004). fMRI-adaptation reveals dissociable neural representations of identity and expression in face perception. J. Neurophysiol. 92, 1830-1839. doi: 10.1152/jn.00155.2004

Yang, E., Tadin, D., Glasser, D. M., Hong, S. W., Blake, R., and Park, S. (2013). Visual context processing in schizophrenia. Clin. Psychol. Sci. 1, 5-15. doi: $10.1177 / 2167702612464618$

Yin, R. K. (1969). Looking at upsidedown faces. J. Exp. Psychol. 81, 141-145. doi: 10.1037/h0027474

Yoon, J. H., D’Esposito, M., Carter, C. S. (2006). Preserved function of the fusiform face area in schizophrenia as revealed by fMRI. Psychiatry Res. 148, 205-216. doi: 10.1016/j. pscychresns.2006.06.002.
Yoon, J. H., Maddock, R. J., Rokem, A., Silver, M. A., Minzenberg, M. J., Ragland, J. D., et al. (2010) GABA concentration is reduced in visual cortex in schizophrenia and correlates with orientationspecific surround suppression. J. Neurosci. 30, 3777-3781. doi: 10.1523/JNEUROSCI.6158-6109. 2010

Young, A. W., Newcombe, F., de Haan, E. H., and Hay, D. C. (1993) Face perception after brain injury: selective impairments affecting identity and expression. Brain 116, 941-959. doi: 10.1093/brain/116. 4.941

Conflict of Interest Statement: The authors declare that the research was conducted in the absence of any commercial or financial relationships that could be construed as a potential conflict of interest.
Received: 12 June 2013; accepted: 26 July 2013; published online: 20 August 2013. Citation: Darke H, Peterman JS, Park S, Sundram S and Carter O (2013) Are patients with schizophrenia impaired in processing non-emotional features of human faces? Front. Psychol. 4:529. doi: 10.3389/fpsyg.2013.00529

This article was submitted to Psychopathology, a section of the journal Frontiers in Psychology.

Copyright (c) 2013 Darke, Peterman, Park, Sundram and Carter. This is an open-access article distributed under the terms of the Creative Commons Attribution License (CC BY). The use, distribution or reproduction in other forums is permitted, provided the original author(s) or licensor are credited and that the original publication in this journal is cited, in accordance with accepted academic practice. No use, distribution or reproduction is permitted which does not comply with these terms. 